\title{
LA EXPRESIÓN ORAL
}

\section{Jesús Ramírez Martínez}

Universidad de La Rioja

\begin{abstract}
RESUMEN. Se propone un acercamiento a la expresión oral como habilidad comunicativa que conviene desarrollar desde perspectivas pragmáticas y educativas. El carácter coloquial de esta expresión ha hecho que se la haya sentido como una destreza de dominio generalizado en los ámbitos de la vida cotidiana y a la que, quizá por esta razón, no se le ha dedicado la suficiente atención educativa. Por ello, se plantea una reflexión que haga tomar conciencia de la necesidad de abordarla didácticamente. Se parte de una concepción inductiva que, a través de algunas experiencias vividas y compartidas por el autor, permita conocer y experimentar modelos de acción didáctica e ir construyendo la teoría propia sobre este enfoque comunicativo y científico que se pretende para esta expresión universal.
\end{abstract}

ABSTRACT. An approach to the oral expression as a communicative skill is proposed, which needs to be developed from pragmatic and teaching perspectives. The colloquial aspect of the oral expression is the reason nhy it has been considered an ordinary skill in everyday life, and for this reason it has not been paid enough pedagogic attention. Therefore, a pedagogic approach is considered absolutely necessary. It comes from an inductive concept which, through certain real and shared experiences lived by the author, can allow us to understand and test teaching activity models. As a result can begin to construct our own theory about this communicative and scientific approach concerning this universal oral expression.

\section{Introducción}

Este artículo pretende aportar algunas experiencias y reflexiones que ayuden a comprender mejor las destrezas de la expresión oral. La estructura de este trabajo intenta responder a un principio pedagógico que creemos pertinente en esta ocasión; consiste en avanzar desde las cuestiones más prácticas y concretas a las teóricas y más abstractas, lo que significa que se utiliza una metodología que va de la práctica a la teoría, de la experiencia a la ciencia, de modo que ésta sea fruto de una dialéctica que conduzca de lo más tangible a la reflexión teórica. Lo hacemos así en coherencia con esta publicación educativa de la Universidad de La Rioja que, a pesar de tener unos receptores y lectores potencialmente universales, concibe y percibe como sus destinatarios primeros a los de la propia universidad. Éstos lo son, principalmente, del ámbito de la educación, bien específicamente como es el caso del alumnado de 
magisterio de las diversas especialidades; bien de otras carreras que están abocadas a la educación; o bien a otros estudiantes y estudiosos cuyas especialidades precisen una buena competencia en comunicación oral.

Intentamos poner en evidencia, y creemos que de modo sencillo para facilitar su comprensión, que con la expresión oral ocurre como con otras cuestiones muy evidentes y es que lo obvio, lo cotidiano -no por ello menos necesario, sino más bien al contrario- es en muchas ocasiones lo más complejo de tratar y de afrontar. Pues bien, para superar esta paradoja ,pensamos que la ciencia pedagógica ha de aportar, especialmente, enfoques didácticos que faciliten la comprensión y los aprendizajes de las habilidades comunicativas de expresión oral, con los procedimientos pertinentes y adecuados que favorezcan la interacción entre el ámbito pragmático y el teórico.

Para ello, el artículo desarrolla una estructura que responde a un patrón ligeramente distinto al modelo académico al uso. Entendemos que nuestra propuesta resulta coherente ya que cohesiona el discurso de modo que permite avanzar desde algunos fenómenos o principios observables más sencillos y lógicos, tales como qué entendemos por un buen oyente y un buen hablante: es decir, por un buen comunicador y las habilidades que le caracterizan, los registros y códigos comunicativos que utiliza, y las referencias culturales y científicas que percibe; y así paulatinamente, hasta llegar a perfilar qué grado de conciencia social y educativa se ha de ir desarrollando en nuestro ámbito familiar, social y profesional.

\section{Competencia comunicativa en expresión oral}

\subsection{Más que hablar y escuchar}

Ser buenos comunicadores en expresión oral, desde la perspectiva de emisores o de receptores, consiste en haber desarrollado una competencia que suponga un dominio de las habilidades comunicativas de lenguaje integrado oral. La expresión oral resulta compleja de valorar, pero todos entendemos que ésta es bastante más que interpretar los sonidos acústicos organizados en signos lingüísticos y regulados por una gramática más o menos compleja; y es más, bastante más, que emitir una serie de sonidos acústicos de la misma índole. Sin duda, que es más.

La pragmática va recordándolo desde hace algunos años, apelando al sentido eminentemente práctico del lenguaje mediante la interpretación de los usos sociales del discurso y de la importancia de los contextos y las situaciones comunicativas que tanto condicionan la información, los mensajes y sus intenciones comunicativas. Es de sentido común que no sólo se interpreta y produce la cadena hablada y sus elementos articulatorios y de tono, es decir, segmentales y suprasegmentales; sino, también, otros que aparecen dentro de la enunciación como los silencios, los ritmos, las cadencias, la intensidad de la voz y la velocidad del habla. Y aún podríamos citar otros como la sonrisa, la risa, el llanto, el sollozo, los suspiros, soplidos, silbos, percusiones, chasquidos, runruneos, canturreos u otros signos acústicos simultáneos que complementan el discurso oral con significados añadidos muy expresivos, ricos y cargados de matices que aportan dosis muy humanas en el paisaje de los claroscuros sig- 
nificativos entre la objetividad y la subjetividad. Incluso, podríamos añadir otros como los gestos de indicación y los movimientos quinestésicos.

La literatura sabe y se beneficia mucho de estos elementos expresivos. Y también la comunicación de la vida cotidiana, es decir, la producida mediante los discursos del día a día con los que nos relacionamos, trabajamos, compramos y vendemos, compartimos y competimos, nos enamoramos y enamoramos, jugamos y peleamos, nos enfadamos y nos alegramos, oramos y renegamos, discutimos y festejamos juntos como vecinos, compañeros, adversarios, amigos, padres, hijos, familia...: En otras palabras, convivimos con el intercambio discursivo oral. Es por ello por lo que la experiencia del día a día y el sentido común nos dicen que esta forma de expresión es más que hablar y escuchar, aunque éstos sean los términos que convencional y familiarmente entendemos por comunicarnos a través de la expresión oral.

Hablar es relacionarse, es intercambiar comunicación, compartir ideas o sentimientos, e intentar llegar a puntos de encuentro; es lograr a estos acuerdos o delimitar los desencuentros, es decidir y obrar en consecuencia. Por ello, comprendemos lo que significa cuando alguien nos plantea "tenemos que hablar"; interpretamos, sin duda, que nos enfrentamos a una situación en la que hay que tratar, compartir o debatir una cuestión o un tema para llegar a comprenderlo mejor conjuntamente e ir actuando según lo tratado y convenido. Y sabemos también que hablar implica, necesariamente, escuchar, mantener una actitud de escucha. En síntesis, puede decirse que la expresión oral consiste en escuchar el lenguaje integrado (estar atento y receptivo a todos los signos que puedan ayudar a interpretar el mensaje) y expresar o hablar el mismo tipo de lenguaje (emitir toda clase de signos que favorezcan la riqueza comunicativa del mensaje).

\subsection{Qué se entiende por un buen oyente/ hablante}

Por un buen oyente se cataloga a alguien que es un buen receptor de cuantos signos pueden ser percibidos e interpretados por sus sentidos, descodificados, y reorganizados con espíritu crítico, clasificando la información y captando las intenciones comunicativas. Alguien que percibe los grados de acuerdo/ desacuerdo, sentido práctico/ de inutilidad, relevancia/ irrelevancia, etc.; Alguien que interpreta correctamente los tonos o claves del registro, sean de humor, seriedad, ironía, enfado, dulzura, romanticismo, irascibilidad o tolerancia... Alguien que se comporta, por supuesto, como un receptor que conoce y practica las actitudes relacionadas con el dominio de las normas de intercambio comunicativo que contemplan el respeto hacia el emisor y los otros interlocutores, y los principios de cooperación y de cortesía comunicativa.

Por un buen hablante se cataloga a alguien que es un buen emisor de cuantos signos puedan ser utilizados para transmitir información y que puedan ser interpretados por un receptor al que ha de tener muy en cuenta. De tal manera que un buen hablante es aquel que considera a su receptor o a sus interlocutores $y$, consciente del grado de complejidad y transcendencia del tema o asunto, acierta con el discurso eficiente en un marco físico adecuado a la situación comunicativa concreta. Este enunciado deberá utilizar la tipología textual más apropiada, el registro y la clave comunicativa más adecuadas, y deberá ser oportuno, es decir, producirse en el momento más apropiado para ser comprendido y lograr, de ese modo, la mayor rentabilidad a su inten- 
ción y necesidad comunicativa, partiendo siempre de máximas comunicativas éticas, eficaces y relevantes (Sperber-Wilson, 1994)'.

Para aportar una visión más práctica, y pensamos que eficaz, recurrimos al esquema que sintetiza algunas de las propuestas de autores de las corrientes pragmáticas (Cassany, 1994). No obstante, podrían aceptarse otras características más como, por ejemplo, las relacionadas con la actitud que se ha de adoptar ante situaciones comunicativas concretas. En éstas resulta relevante la puesta en escena, la distancia entre los interlocutores, la vestimenta, los movimientos, posturas, miradas, gestos y todas las iniciativas comunicativas que favorezcan el intercambio mediante la generación de un clima de interacción comunicativa lo más grata y eficaz posible. La calidez en la interacción y la simpatía, entre otras, son condiciones muy positivas para el éxito comunicativo.

\begin{tabular}{|c|c|}
\hline \multicolumn{2}{|c|}{ ALGUNAS CARACTERÍSTICAS DEL COMPORTAMIENTO DE UN BUEN COMUNICADOR ${ }^{2}$} \\
\hline Un buen oyente & Un buen hablante \\
\hline - Adopta una actitud activa: se interesa & $\begin{array}{l}\text { Tiene en cuenta a la audiencia y } \\
\text { su relación con el tema }\end{array}$ \\
\hline $\begin{array}{l}\text { Mira o interactúa con el orador } \\
\text { y lo respeta }\end{array}$ & · Planifica el discurso \\
\hline - Intenta ser objetivo: escucha lo que dice & - Centra el tema y adecua el tono \\
\hline $\begin{array}{l}\text { Conecta con la intención del emisor } \\
\text { aunque con espíritu crítico }\end{array}$ & - Respeta los principios de textualidad \\
\hline $\begin{array}{l}\text { Descubre las ideas principales y } \\
\text { secundarias y las jerarquiza }\end{array}$ & $\begin{array}{l}\text { Cuida los principios de cooperación } \\
\text { comunicativa }\end{array}$ \\
\hline Descubre las intenciones & $\begin{array}{l}\text { Cuida la imagen propia, los gestos y todos } \\
\text { aquellos signos que forman el discurso }\end{array}$ \\
\hline . Valora lo escuchado & - Observa las reacciones de la audiencia \\
\hline - Aprecia la intervención del orador & - Es ético y sincero \\
\hline - Reacciona al mensaje & - Evita lo monocorde \\
\hline - Maneja los turnos de habla & - Cuida los principios de cortesía \\
\hline - Otras & - Otras \\
\hline
\end{tabular}

Entendemos que en este esquema, sin pretender ser exhaustivos, figuran algunas de las condiciones y comportamientos propios de personas preocupadas por desarro-

1. SPERBER, D. y WILSON, D. (1986), La relevancia. Comunicación y procesos cognitivos. Madrid, Visor, 1994.

2. Se aportan términos sobre conceptos desarrollados por la pragmática que son muy usados en la pedagogía del lenguaje denominada como del enfoque comunicativo. 1. Principios de textualidad: Coherencia, cohesión, adecuación, estilo y corrección. 2. Principios de cooperación comunicativa: Cantidad, calidad, relevancia y modo. 
Ilar una competencia comunicativa aceptable. Creemos que se dan pautas para ir induciendo cuáles son las actitudes y aptitudes que se han de ir educando y practicando para conseguir ser diestros y habilidosos a la hora de ser comunicadores competentes, tanto desde la perspectiva comprensiva como expresiva. Invitamos a reflexionar sobre ellas.

\section{Habilidades y microhabilidades}

\subsection{Habilidades comunicativas que desarrollamos}

Si tomamos como referencia las características y destrezas que acompañan a los comunicadores competentes, hemos de asumir que es necesaria la conjunción y armonización de habilidades de distinto ámbito, susceptibles de ser jerarquizadas: algunas están relacionadas con los conocimientos del emisor y receptor sobre el tema, otras con la creatividad, otras con la organización de las ideas, otras con los aspectos formales, sean acústicos, de presencia, comportamiento y saber estar, dicho en términos corrientes. A nadie se le escapa lo que estropean un discurso y una situación comunicativa los tonos inadecuados, las manifestaciones agresivas, el talante tenso, los gestos poco respetuosos o intimidatorios por muy sutiles que pretendan ser. Del mismo modo, todos sabemos lo que ayudan a la comunicación los gestos que inspiran serenidad, sosiego, empatía o conexión comunicativa tales como la modulación adecuada de la voz, el tono cercano y cariñoso, la simpatía, la clave de confianza o el énfasis de complicidad positiva que genera sintonía emotiva y comunicativa. Sin duda que son recursos que ayudan a desarrollar estas destrezas y todas las habilidades y microhabilidades que las van haciendo posibles (Cassany, 1994: 100-192 )³.

Hemos de aclarar que utilizamos los términos destrezas y habilidades como sinónimos en estos momentos con el significado compartido de ser "diestros o hábiles" a la hora de lograr que el lenguaje funcione, es decir, que se consigan las funciones del lenguaje. Entendemos estas últimas con el significado de para qué se usa el lenguaje, como qué funciona, con qué finalidad, para qué sirve, indiferentemente de que tomemos la catalogación canónica de Jakobson (expresiva, apelativa, estética, metalingüística, fática y representativa); la pragmática de Halliday (instrumental, reguladora,

3. Conviene dar cuenta del binomio terminológico destreza/ habilidad. Aunque hay autores que lo perciben como sinónimo y a ello tendemos en este artículo, también pueden deducirse distintos ámbitos de uso: 1. En el mundo educativo se suele hablar más de destrezas comunicativas con un matiz de ser un diestro y buen comunicador atendiendo a cualquier función comunicativa. 2. En el mundo de la comunicación social más general se tiende a usar el término habilidades, quizá por el matiz retórico que se le supone como el "arte de la persuasión" que, obviamente, y no queremos profundizar ahora en ello ni entrar en debates, no abarca las diversas funciones del lenguaje. Entendemos que éste tiene más funciones que la de persuadir, como puede ser la de representar con objetividad, acompañar en el dolor, generar su propia visión del mundo, fomentar la propia creatividad, la propia estética, etc. Y el término "habilidad" en las acepciones del diccionario ya contempla algunas otras acepciones como "// 4. Enredo dispuesto con ingenio, disimulo y maña. // hacer alguien sus -es. fr. coloq. Valerse de toda su destreza y maña para negociar y conseguir algo." DRAE, 2001: 1182. O, según el diccionario de uso de Moliner, 1999: 1447, también adquiere a veces valores de astucia, picardía y engaño, además de pericia. 
interaccional, personal, heurística, imaginativa y representativa); o las de carácter más educativo de las corrientes del enfoque comunicativo como la de Reyzábal, 1993: 5960 (comunicativa, representativa y reguladora) ${ }^{4}$.

Desde el ámbito educativo se considera que se han de desarrollar con un alto grado de competencia las destrezas y/ o habilidades comunicativas, como son "las cuatro destrezas": Las comprensión oral o escucha, y la expresión oral o habla; la comprensión de la escritura o lectura, y la expresión escrita o escritura. Y, a la par, en el ámbito de la didáctica actual, se habla de habilidades y microhabilidades como procedimientos metodológicos para desarrollar plenamente estas destrezas (Cassany, 1994: 107 y ss.; 148 y ss.). Por su carácter práctico, remitimos especialmente a lo planteado por este autor y a algunos de los modelos que aporta, tanto en el apartado de las microhabilidades cuanto en las actividades didácticas que sugiere como modelos.

\subsection{Algunos modelos y ejemplos}

Ya desde la época clásica se ha recurrido a los modelos canónicos que servían de referencia. A veces de un modo demasiado encorsetado, aunque no tanto por los propios paradigmas, cuanto por la actitud de quienes inducían u obligaban a reproducirlos de un modo casi idéntico. $Y$ esos enfoques, en los que se impuso su reproducción con una cierta rigidez, no contribuyeron a fomentar la creatividad de quien debía aprender. Pero, por fortuna y por "ley de vida", o por "mandato" de la propia especie, el ser humano ha ido rompiendo o ampliando los moldes para ir autoconstruyéndose sobre la cultura que le sirve de base y referencia. $Y$ se han ido generando otras estrategias, procedimientos y modelos comunicativos que han complementado a los anteriores y ampliado la cultura. En otras palabras, que no se han aceptado históricamente los modelos únicos, que no los hay, ni el ser humano se ha dejado esclavizar ni enajenar por ellos.

Los estudios sobre la adquisición y el desarrollo del lenguaje, muy recientes y de gran actualidad, están tratando e investigando muy a fondo los distintos factores que intervienen en la consolidación de una buena competencia comunicativa oral; especialmente, desde la perspectiva del lenguaje integrado, con el lenguaje como principal vehículo comunicativo de la especie y específico de ella. Estos estudios confirman la vertebración de dos procedimientos: Uno, imitativo de los modelos discursivos orales que le llegan y experimenta el niño o niña que adquiere y desarrolla su lengua materna. Dos, el creativo que pone en marcha este nuevo usuario. No cabe duda de que los dos, imitación y creación, son fundamentales para la consolidación de la competencia citada. Pues bien, pensamos que de modo similar, aunque no idéntico, se ha de afrontar el proceso de capacitación comunicativa para ser hábiles en la expresión oral: Haciendo uso de la propia creatividad comunicativa y del estilo personal, y mediante el aprovechamiento de los modelos más correctos y eficaces, recreados adecuadamente según las situaciones comunicativas a las que conduzcan las necesidades personales, relacionales y convivenciales. Lógicamente que en el marco del sistema comunicativo común del lenguaje y de la lengua dada, y de las normas de uso.

4. REYZÁBAL, M.V. (1993), "La lengua, eje de formación individual y social", en Bordón, 45. Madrid, Sociedad Española de Pedagogía, Universidad Complutense. 
Dice la ciencia lingüística que el concepto de norma es el conjunto de buenos usos que desarrolla y va fijando una comunidad de hablantes de una lengua dada para regular su utilización de modo que se asegure la comunicación entre quienes la usan y, a la vez, la propia pervivencia del sistema. Llamémosle norma, competencia con criterios de corrección o como se prefiera, según la adscripción científica a la que nos sintamos más cercanos, lo cierto es que se necesita esa referencia normativa que regule el carácter convencional del lenguaje de modo que se mantenga el convenio de manejar unidades comunicativas y lingüísticas comunes que aclaren y no confundan. Dicho de otro modo, es evidente que los modelos son necesarios y que se parte de ellos $y$, por tanto, que deben tomarse como referencia, tanto desde el punto de vista conceptual, como procedimental y actitudinal. Nos parece muy interesante y pertinente esta forma triádica de afrontarlos, en sintonía con el espíritu y la planificación del Sistema Educativo Actual. Coincidimos con su planteamiento que contempla contenidos diversos que tienen que ver con el saber, el saber hacer y el saber hacer con buena intención y con sentido ético, con valores de vida en el marco de los derechos humanos y de la naturaleza.

\section{Comunicación y Lengua: Lenguaje integrado}

\subsection{Recordemos: la expresión oral es más que escuchar y hablar}

La comunicación es un concepto más amplio que el lenguaje. Es verdad que la expresión lingüística es siempre comunicación; sin embargo, no toda comunicación es siempre lingüística. Obviamente, los sistemas no verbales lo corroboran. Incluso, resultaría bastante arriesgado aceptar que existe comunicación lingüística en estado puro. Más bien habría que aceptar que cualquier expresión lingüística está mediatizada o complementada por otros sistemas de comunicación no lingüística o no verbal. Si analizamos, por ejemplo, cualquier texto escrito, es evidente que el tipo de letra, el sopor te, los formatos u otros elementos gráficos o plásticos aportan valores significativos que van a integrarse en el "lenguaje". Y, si hacemos lo mismo con un discurso oral, es claro, asimismo, que la presencia e imagen de los emisores y receptores resulta de gran relevancia; así como los espacios que ocupan, sus vestimentas y ornamentaciones, la expresión corporal y los gestos, especialmente los de indicación, además de la modulación de la vOz, forma de respirar, velocidad del habla, acompañamiento de sonrisas, risas u otras manifestaciones que también van a integrarse en el "lenguaje". Pues bien, escuchar y hablar, con la complementación del manejo de todos estos signos que hemos citado, constituyen las destrezas expresivas del lenguaje integrado.

\subsection{Lenguaje integrado}

En el epígrafe anterior hemos definido, de un modo inductivo, el carácter natural del lenguaje integrado, de modo que podemos decir que, en la práctica, no existe otro. No obstante, sí podemos y debemos aceptar que existen un sistema de lengua y unos universales del lenguaje que, desde el punto de vista descriptivo, constituyen una base estructural y funcional del lenguaje en el sentido gramatical del término, especialmente, desde la perspectiva de las correspondientes escuelas lingüísticas. 
Pero, desde el punto de vista práctico del uso, es evidente que tenemos que partir del lenguaje integrado. Y, si hemos de centrarnos en el uso habilidoso de la expresión oral, es claro que hemos de partir de una concepción que contemple este lenguaje que integra elementos verbales y no verbales. Por la sencilla razón de que no podemos diseccionar aquello que es funcionalmente inseparable para que sirva en la expresión puntual concreta; como no es posible separar en la realidad de nuestra existencia vital nuestro cuerpo de nuestra ánima o soplo llamado vida. En la expresión oral somos también nuestra presencia, y ella comunica con todo tipo de signos de modo inconsciente y consciente. Pues bien, cuanto más consciente se sea de la esencia comunicativa dual de todo signo, más posibilidades tendremos de un uso más eficaz y correcto de estos signos que constituyen la mezcolanza armónica del lenguaje integrado.

\subsection{Lo que dice el Sistema Educativo}

El Sistema Educativo contempla el lenguaje de modo similar al que se viene describiendo. Este hecho no supone que su currículum oficial va a ir marcando rígidamente las pautas educativas sin más; sino que éste, como no podría o no debería ser de otra manera, ha de adecuarse a nuestras necesidades comunicativas y construir un currículum específico que responda y resulte útil para cubrir estas necesidades.

En cualquier caso, si se le da un breve repaso, nos encontramos con la siguiente distribución según los distintos niveles de educación obligatoria ${ }^{5}$ :

- Educación Infantil: Dentro del Área de La Comunicación y la Representación: 1. Lenguaje oral. 2. Aproximación al lenguaje escrito. 3. Expresión plástica. 4. Expresión musical. 5. Expresión corporal. 6. Relaciones, medida y representación en el espacio.

- Educación Primaria: 1. Usos y formas de comunicación oral. 2. Usos y formas de comunicación escrita. 3. Análisis y reflexión sobre la propia lengua. 4. Sistemas de comunicación verbal y no verbal.

- Educación Secundaria Obligatoria: 1. Usos y formas de comunicación oral. 2. Usos y formas de comunicación escrita. 3. Análisis y reflexión sobre la propia lengua. 4. La literatura. 5. Sistemas de comunicación verbal y no verbal.

Esta distribución de contenidos del propio Currículum Oficial es un buen indicador del carácter integrador de la comunicación y de la dimensión plural del lenguaje a través de su realidad de lenguaje integrado. Subyace el enfoque comunicativo y prima el desarrollo de las cuatro destrezas. Resulta relevante el modo de plantear las destrezas de la lengua oral y escrita bajo el epígrafe de "usos y formas de la comunicación oral/ escrita". Interpretada esta enunciación desde una perspectiva pragmática, podría traducirse como 'discursos usados, que se usan y por usar, y formas de hacerlo, desde una visión comunicativa de lenguaje integrado'.

\subsection{Lo que puede hacerse en las clases}

Conviene adelantar que, llegados a este punto, me parece un buen principio hablar desde lo experimentado por uno mismo si ello es posible, y no sólo de lo leído o escu-

5. MEC (1992), Cajas Rojas. Madrid, MEC. 
chado. Mi experiencia educativa o docente, que la entiendo como un acompañamiento comprometido en los procesos de aprendizaje con el fin de facilitar las cosas a quien quiere aprender, abarca los ámbitos de las Ilamadas educación formal y no formal. Y con algunos matices, el método desarrollado en las diversas aulas en las que he compartido experiencias ha sido muy parecido. Incluso, podría decir que los procedimientos de las experiencias en educación no formal han aportado más pautas a la formal que al revés: Quizá haya sido por el carácter no tan formal de la expresión oral.

Experiencias propias en educación no formal: Con grupos de adultos que pretendían el desarrollo de habilidades para el desenvolvimiento en el medio social o laboral. Regularmente han sido grupos de personas adultas que han precisado de una competencia comunicativa específica para situaciones concretas: trabajadores, cooperativistas, futuros agentes de desarrollo turístico, servicios al público, asistencia a domicilio, grupos de mujeres para favorecer el diálogo en el ámbito afectivo y personal... Otros han sido grupos desfavorecidos, inmigrantes o no, que han precisado apoyos para la oralidad y las relaciones en la vida sociolaboral y administrativa. Experiencias como el "Plan Piloto de Educación de Adultos de Melilla" y el "Programa de Educación Básica de Adultos de El Salvador (El Salvador, C.A.)", constituyen modelos de interés para este tipo de habilidades comunicativas (Ramírez, 1997) ${ }^{6}$. Aportan elementos muy significativos como la figura del facilitador como 'educador, docente, maestro'; y el concepto-unidad educativa círculo como 'grupo de personas en formación educativa que se agrupan en torno a una estructura comunicativa circular, con o sin mesas, sentados en el suelo, bancos, sillas o troncos de árboles'. Lo hacen con el fin de hablar de sus cosas vitales y aumentar sus competencias comunicativas e intelectuales, con el fin de alfabetizarse en el sentido freiriano de concienciarse, es decir, de tomar conciencia de sus necesidades, y capacitarse para ser más autónomos y desenvolverse mejor en el medio social, laboral, económico o administrativo. De ese modo se tendrá más acceso a una vida con un grado mayor de libertad, dignidad y justicia. Todo ello a través de la palabra, de su voz que es la expresión de su dignidad como personas (Freire, 1970).

Experiencias en educación formal elegida: Principalmente, en torno a la asignatura de libre elección, Habilidades comunicativas en expresión oral, impartida en la Universidad de la Rioja dentro del programa "Innovación Docente" , que ha aglutinado a alumnado universitario de diferentes carreras como Derecho, Humanidades, Trabajo Social, Magisterios, Filologías y otras cursadas por algunos alumnos extranjeros que completan estudios en esta universidad, y que consideran que precisan mejorar su competencia en expresión oral.

Experiencias en educación formal "oficial": Compartidas con el alumnado de la Sección de Magisterio de la UR al que, desde la puesta en marcha de la LOGSE, se le

6. "Plan Piloto de Educación de Adultos para el Desarrollo Integral de Melilla." Melilla, 1989/1992. "Plan de Educación Básica de Adultos de El Salvador, C.A." San Salvador, El Salvador C.A., 1993/ 1996. En ambos, el autor fue coordinador de formación y de materiales educativos.

7. "Plan de Actuación y Apoyo para la Mejora e Innovación Docente", de la Universidad de La Rioja, premiado, con otros cinco de otras tantas universidades, por el Consejo de Coordinación Universitaria en el II Plan de Calidad de las Universidades. 
ha impartido la expresión oral como una de las destrezas fundamentales del Sistema Educativo Español, tal como hemos visto anteriormente.

Con todos ellos se ha desarrollado una serie de actividades, obviamente que adaptadas a cada grupo, que parten del enfoque comunicativo en su sentido más práctico. Sirva de ejemplo el propio programa de la asignatura ${ }^{8}$. Grosso modo, paso a exponer parte de la metodología utilizada citando algunas actividades, entre las que figura, por ejemplo, la elaboración de un cuaderno hecho a mano siguiendo las pautas de un discurso instructivo donde, entre otras cuestiones, van a reflejar sus percepciones, vivencias, reflexiones, experiencias y conclusiones sobre las habilidades comunicativas en expresión oral. El cuaderno, en concreto, contendrá los siguientes textos: ${ }^{9}$

- Texto/ discurso introductor: presentación, introducción, ...

- Diario descriptivo-reflexivo de aula-clase: registro y recapitulación sobre las actividades y vivencias durante la impartición conjunta de la asignatura.

- Guiones o textos elegidos por el alumno para su oralización, dependiendo de sus necesidades y preferencias, que irán acompañados de su producción oral grabada en una casete o en cinta de vídeo.

- Artículo propio donde se refleje su percepción sobre la exposición oral.

- Desarrollo personal del temario de la materia: construcción de la teoría propia sobre la asignatura. ${ }^{10}$

- A modo de conclusión: síntesis de cierre.

Durante el curso, además de esta actividad, que es de recapitulación, se practican y comparten a diario situaciones comunicativas que implican saludarse, presentarse, presentar a otros, despedirse, solicitar, dar información, establecer protocolos comunicativos, escuchar, hablar, opinar, conversar, dialogar, debatir, negociar, argumentar,

8. "Habilidades comunicativas en expresión oral": Objetivos: 1. Valorar la expresión oral como vehículo comunicativo universal esencial para el desarrollo humano, personal y profesional, y como un instrumento básico para la convivencia y la generación de valores de justicia y paz. 2. Desarrollar los métodos, procedimientos y actividades necesarios para el desarrollo de la habilidad comunicativa en la expresión oral: escuchar y hablar. 3. Conocer los principios pragmáticos, normativos y científicos de la expresión oral. Contenidos: 1. Marco teórico: 1.1. La expresión oral y el lenguaje integrado. 1.2. Las dificultades de expresión oral y el cuidado de la voz. 2. El habla cotidiana: La interacción comunicativa diaria. 3. La conversación: Los textos orales dialógicos. 4. La exposición: El habla y el parlamento en público. 5. La narración, la descripción y la recitación: Expresión oral de carácter literario. 6. Tecnologías, medios de comunicación y expresión oral. Metodología: Inductiva, constructivista y pragmática, desde los enfoques comunicativos que sintonizan con el espíritu educativo actual para el adecuado desarrollo de la didáctica del lenguaje y la comunicación. Evaluación: 1. Evaluación continua de tareas y actividades de expresión oral durante curso. 2. Prueba final: Desarrollo de una situación comunicativa en expresión oral.

9. Se utiliza como recurso para sentir que también en expresión oral "queda algo" y que las palabras no "se las lleva el viento". Proceso reflexivo para percibir las diferencias/ semejanzas entre la expresión oral y escrita.

10. De esta manera se consolida la metodología propuesta para la asignatura desde la doble perspectiva de constructivismo y valoración de la expresión oral desde un punto de vista actitudinal: 1 . Construyendo la teoría propia en el citado cuaderno. 2. Destilando en una práctica reflexiva la experiencia con el fin de poner en valor, mediante el trabajo escrito que "almacena" la información y las vivencias que dan valor a la propia expresión oral. 
dar instrucciones, reclamar, exponer, describir, narrar, recitar y cantar. Así como valorar las actuaciones comunicativas, propias y de otros, percibidas directamente y reflejadas en el espejo, grabadas en casete y en videocámara, sobre presuntas, pero muy verosímiles y reales situaciones comunicativas y actos de habla cotidianos, profesionales o puntuales. También se observan y analizan situaciones comunicativas reales de los medios de comunicación, o directamente acudiendo a conferencias, coloquios, charlas-coloquio, debates, ponencias, etc., del ámbito social, cultural y universitario que, posteriormente, se reproducen en el aula.

\section{Desde la lingüística y las ciencias de la comunicación}

\subsection{La postura llamada tradicional y la del enfoque comunicativo}

Los planteamientos tradicionales sobre la expresión oral resultan bien curiosos. Por una parte se ha producido un desinterés educativo-escolar bastante grande por el desarrollo de habilidades en expresión oral. Como todo el mundo hablaba, se suponía que no tenía tanto interés su abordaje educativo. Por otra, se le dio gran valor desde la perspectiva retórica, y fueron las clases dirigentes de los ámbitos de cualquier poder o grupo predominante (político, administrativo, religioso, jurídico, etc.) quienes desarrollaron las ciencias de la oratoria y la retórica a niveles ya conocidos. El sistema escolar, sin embargo, se centró mucho más en la expresión escrita y en alguna tipología oral especializada cercana a la retórica y a la literatura.

Junto a esta concepción histórica se sitúa actualmente el enfoque comunicativo que aboga, en su filosofía educativa, por el desarrollo práctico de las destrezas orales como base del desarrollo personal, educativo y sociolaboral que favorece la convivencia armónica en el ámbito de lo privado y lo público.

\subsection{Las nuevas tecnologías al servicio de la comunicación global e integral}

Las nuevas tecnologías, que permiten almacenar y trabajar científica y comunicativamente la voz y la imagen, y, por tanto, la expresión oral, han favorecido la pedagogía de esta expresión mediante didácticas que las utilizan para un abanico de actividades casi sin límites. Las esperanzas en este tipo de recursos son inmensas; pero también habrá que ir generando una ética de su utilización que vele y, sobre todo, ayude a generar espíritu crítico que valore las informaciones, intenciones e intereses que pueden subyacer en este tipo de mensajes.

La necesidad de llevar a cabo actividades prácticas por parte del alumnado y los grupos, y el uso de recursos tecnológicos implican una serie de condiciones que han de ser tenidas en cuenta para hacer posible una didáctica de la expresión oral razonable y eficaz. Una didáctica de la expresión oral que permita y favorezca todo tipo de habilidades, tanto de escucha y comprensión como de habla o expresión, supone que se debe contar con las condiciones básicas necesarias para llevar a cabo una labor educativa de calidad, y que podrían sintetizarse en las siguientes:

- Grupos reducidos y espacio suficiente, funcional y polivalente. 
- Mobiliario que permita generar situaciones-espacios comunicativos diversos con una relativa facilidad, así como la habilitación de zona de estrado apropiada, con atril incluido.

- Sistema de iluminación que permita dirigir la luz o focalizarla sobre algunos espacios y dejar en penumbra otros.

- Condiciones para la utilización de recursos tecnológicos para la comunicación: televisión, vídeo, videocámara, casetes, retroproyector, etc.

- Zona amplia de espejos para las expresiones corporal y musical que complementan el lenguaje integrado, es decir, la expresión oral.

\subsection{El llamado estado de la cuestión}

Siguiendo con el hilo metodológico inductivo expuesto al principio, es hora de ir deduciendo desde lo inducido: 1. Históricamente la preocupación por generar habilidades comunicativas en expresión oral, desde el punto de vista educativo formal, no ha sido muy grande salvo por parte de los grupos dirigentes que la desarrollaron considerablemente con la oratoria y la retórica. Por supuesto que, desde la perspectiva educativa familiar, todos los padres han estado muy atentos a que sus hijos hablaran lo mejor posible y se desenvolvieran con soltura y acierto. 2. En estos momentos, la confluencia de factores como la importancia de la globalización comunicativa y su relación con el uso del poder de cualquier ámbito, así como la abundancia de recursos tecnológicos para el lenguaje integrado, han hecho que los propios sistemas educativos lo hayan abanderado y hayan hecho de la expresión oral la base universal de la comunicación. Ahora se asume de modo general que la didáctica de esta expresión en lengua materna también es necesaria, deseable y posible. En segundas y terceras lenguas, esto se ha percibido siempre de modo clarísimo por razones obvias: si no se dominaba la expresión oral, no se entendía y, en consecuencia, no había posibilidades de comunicación.

Por ello, a partir de los años 90, han ido apareciendo métodos, prácticas y estudios que van generando una corriente pragmática y teórica, con respaldo didáctico y bibliográfico, que constituyen la base de la ciencia de la comunicación en expresión oral. Programas de doctorado, métodos de oralidad, nuevas tecnologías al servicio de la oralidad, publicaciones sobre experiencias concretas en revistas de educación como Cuadernos de Pedagogía, así como una bibliografía tanto de enfoque pragmático como toérico-científico van dando cuerpo a esta necesaria vertiente educativa.

\section{La construcción de nuestra teoría en consonancia e interacción con la competen- cia comunicativa propia}

Como se decía al principio, ocurre con cierta frecuencia que no nos damos cuenta de lo obvio. Esto pasa, por ejemplo, con la expresión oral, tan frecuente, cotidiana y natural. Resulta tan familiar, tan al alcance de todos, que puede parecer algo común, poco meritorio o al menos no perteneciente a un ámbito de prestigio. Y esto mismo sucede a la hora de abordar proyectos en los que se desarrollen programaciones de acciones educativas de expresión oral. Como decía un alumno en una primera reacción, "escuchar tampoco tiene tanto mérito, si fuera hablar..., aún..." 
Sin embargo, todos sabemos y sentimos que, como vehículo comunicativo universal, por supuesto que es necesario desarrollar habilidades que favorezcan la expresión oral de calidad. Da prestigio hablar bien y, desde luego, facilita la autoconstrucción de las personas y de la sociedad que se constituye a partir de la relación, fundamentalmente comunicativa, entre ellas. Aparentemente, abordar la enseñanza-aprendizaje de esta destreza que, en lo básico, está adquirida y con una competencia dentro de los parámetros considerados "normales", puede parecer tarea poco rentable desde el punto de vista academicista. Todavía más si nos referimos a la lengua materna, pues puede extrañar que se haga hincapié en la expresión oral en nuestra lengua, en el habla de ese idioma en el que hemos empezado a demandar, sentir, pensar, amar, relacionarnos con nuestros entornos afectivos cercanos y con nuestra cultura. Parece que se tiende a pensar que, en fin, si eso lo hacemos todos los días...; si aún fuera en un idioma o lengua extranjera..., pero en la nuestra...

Naturalmente, este autor considera que es un error el planteamiento citado por él mismo en clave de ironía. Error bienintencionado, sin duda, pero error al fin y al cabo. Recordemos que venimos manteniendo que la expresión oral es más, bastante más que escuchar y hablar en registro coloquial en una lengua dada. Los mismos alumnos de lengua materna extranjera manifiestan que perciben esto con claridad al decir "también tengo problemas en expresión oral en mi propia lengua...", mientras muchos de sus compañeros de lengua materna asienten con la cabeza u otros gestos afirmativos. Tendremos que ir planteando, por tanto, algunos principios que ayuden a romper otras tantas ideas que impiden que se aborde con naturalidad y sentido práctico la necesaria pedagogía de la expresión oral. Y debemos hacerlo porque siempre ha constituido una gran dificultad añadida esa presunción de que el manejo de la oralidad es una destreza de tenemos de modo "natural", como un rasgo de nuestra personalidad, como una característica psicológica o psicolingüística forjada desde la más tierna infancia. Aceptando que algo de ello hay y que las experiencias y el modo de abordar la comunicación oral en la infancia condicionan desarrollos posteriores, no es menos cierto que se puede y se debe seguir trabajando educativamente el desarrollo de otros procedimientos educativos y comunicativos que nos hagan más diestros y más hábiles, más eficaces en nuestra comunicación. Actualmente parece que, al menos en los foros educativos, se plantea la necesidad de este tipo de programas. El propio Sistema Educativo Español así lo confirma. Y resulta lógico porque, si hemos de ser coherentes con los principios de educar para la vida y no sólo para el mero desarrollo escolar, académico, intelectual o profesional, se ha de incidir en las destrezas comunicativas necesarias para un desarrollo global e integral del ser humano. De este modo se conseguirá que se autoconstruya en la necesaria armonía consigo mismo, con sus entornos afectivos, con sus entornos sociales y, más tarde, en sus ámbitos profesionales y administrativos. Es decir, dicho a lo claro, armónicamente, de modo que haya sintonía y coherencia entre su vida privada, pública e, incluso, personal, y en todas sus dimensiones: autoconcepto, autoestima, espiritualidad, creatividad, estética, etc.

Esto que parece tan evidente se encuentra con grandes dificultades a la hora de abordarse en programas educativos concretos. Resulta mucho más habitual y se siente como más "normal" trabajar la lengua escrita, la literatura, la gramática y otros contenidos de comunicación y lenguaje que la expresión oral. Del mismo modo, también 
parece que resulta lógico, muy necesario y de gran utilidad enseñar y adquirir destrezas de expresión oral en una lengua extranjera porque se siente, realmente, que "hay mucho que aprender". Sin embargo, en lengua materna es como si se prejuzgara que "aprender a escuchar y hablar" fuera una tarea poco especializada, poco "científica" y redundante porque se parte de la idea cierta de que "todos los niños saben hablar y se entienden entre ellos y entienden las cosas y las expresan..."; eso sí, según las habilidades comunicativas de cada quien -sentidas como inherentes a la personalidad de cada uno y en alguna medida difícilmente alterables. Pues bien, es necesario caer en la cuenta de que hay que desarrollar la expresión oral tanto en lengua extranjera como en la materna, y la experiencia nos dice que pueden y deben seguirse metodologías semejantes, prácticas, para su desarrollo en ambas lenguas: ambas saldrían muy beneficiadas y las capacidades comunicativas del hablante, también.

Otra dificultad que se percibía era la sensación de una cierta carencia de métodos evaluadores rigurosos y objetivos para esta expresión; especialmente, si se la comparaba con la escrita en la que los textos son tangibles y permanentes y existe una vasta tradición educativa. Como se dice coloquialmente, "lo escrito, escrito queda"; sin embargo, el habla, la comprensión... ¿cómo la valoramos desde un punto de vista práctico, con criterio académico o escolar, muy mediatizado por la gran valoración de lo permanente y contrastable en todo momento? Pues bien, recurriendo de nuevo a Cassany (1994: 129; 186-187), a modo de ejemplo, podemos comprobar que se cuenta con tablas de observación y evaluación que constituyen un referente práctico y de gran interés. Además, con las nuevas tecnologías se registran y almacenan discursos grabados permanentes que pueden revisarse cuantas veces sea necesario con métodos más sencillos y cómodos, incluso, que la lectura, sin desmerecer para nada esta destreza.

Quizás haya que ser más reflexivos, comenzar a observar qué es lo que se valora, qué es lo que tiene valor y poner en valor la expresión oral, y caer en la cuenta del gran poder de la palabra hablada y de su relevancia en la vida cotidiana: artistas, comunicadores, ideólogos, sindicalistas, políticos, marcadores de tendencias, locutores, personajes públicos..., todos ellos, como personas de reconocida capacidad de crear opinión y ejercer su modelo comunicativo y su influencia a través de su expresión oral en medios de comunicación como la radio y la televisión, nos dan ejemplo de ello. Y, si nos centramos en las relaciones humanas de cercanía e, incluso, sociolaborales, la expresión oral lleva también la voz cantante, aunque los documentos escritos sean los que acaben almacenando la información más elaborada de ciencia, técnica, de relaciones comerciales o jurídicas. Pero, al fin y al cabo, éstos tan sólo acaban recogiendo la síntesis de todas las intercomunicaciones e intercambios informativos en lenguaje integrado, orales principalmente, entre quienes van hablando, reflexionando, negociando significados y llegando a los acuerdos y a los textos pertinentes.

La economía y el mundo del marketing, esencialmente pragmáticos, lo han interpretado comercialmente de modo inmediato: es obvio que el negocio de las telefonías es muy superior al del correo convencional y que el lenguaje integrado que supone el uso del móvil (habla y mensajería, especialmente juvenil, es una tendencia y un fenómeno semiótico bien interesante en estos momentos) son una buena muestra de la importancia de la expresión oral. Sin embargo, la sentimos una expresión tan cerca- 
na, coloquial y natural que a veces no se la valora lo suficiente. Tendemos a tomarla en consideración cuando hay problemas con ella, cuando se percibe que el habla de alguien se deteriora. Es seguro que cualquier familia o educador levantará todas las alarmas si el hijo o educando pierde alguna destreza oral o algún grado de esta capacidad comunicativa por razones de audición deficiente, vocalizaciones poco adecuadas o pérdida de riqueza comunicativa de cualquier índole. La reacción es inmediata, del mismo modo que es automática la alarma cuando un niño no comienza a hablar en sus etapas y edades entendidas como naturales; o cuando alguien pierde estas capacidades comunicativas de forma anómala: por enfermedad, accidente o deterioro de los sentidos o por cualquier otro motivo. Es interesante, incluso, que se tenga en cuenta que las terapias o alternativas a estos problemas de oralidad, diseñadas ex profeso, se va comprobando que, además de cumplir con su objetivo específico para mejorar las capacidades comunicativas de estas personas afectadas, han servido, también, para lograr mejoras comunicativas de expresión oral en personas corrientes sin ese tipo de dificultades o de necesidades especiales.

Si reflexionamos sobre lo expuesto, puede observarse que, en alguna medida, parece que estemos justificando la necesidad de una pedagogía de la expresión oral. Y ciertamente lo estamos haciendo; pero no en la idea de intentar justificar la legitimidad académica de la expresión oral, que sin duda la tiene, sino como procedimiento para vivirlo como algo lógico y natural. Porque lo evidente y natural es que el habla, la expresión oral, es absolutamente necesaria para comunicarnos, es la expresión general y universal, y es esencial para establecer las relaciones humanas en cualquiera de sus condiciones o ámbitos. Y si es así, también hemos de educar, profesionalmente y con rigor, esta destreza de modo que seamos habilidosos en su uso. La expresión oral, como cualquier actividad humana, es susceptible de mejoría. Y lo es porque las personas somos capaces de superarnos, y lo hacemos de modo permanente por mandato genético natural, y porque nuestra capacidad transformadora nos hace responder de modo natural al empeño de la especie por superar cuantos retos supongan un avance. $Y$ dado que el lenguaje, especialmente en su vertiente oral, tiene una función instrumental tan rentable, todavía más, ya que se convierte en catalizador y multiplicador muy poderoso de todas las capacidades mentales, motoras y transformadoras.

Principios que fundamentan la esencia del hombre en términos kantianos, como la importancia de tomar la palabra y el tener derecho a voz, y, en consecuencia, a opinar, a decidir y a hacer, son la base de la convivencia humana en sociedades donde impera la justicia propia de una sociedad democrática basada en los derechos humanos.

\section{A modo de conclusiones}

Tras la exposición desarrollada en el artículo, pensamos lo siguiente:

- La expresión oral se ha trabajado poco educativamente por no tener la suficiente conciencia de ser susceptible de mejora a través de procesos pedagógicos.

- Actualmente se va percibiendo la necesidad de mejorarla por ser el vehículo universal de comunicación y por su gran rentabilidad en todos los ámbitos, tanto personales como privados o públicos, hasta tal punto que la contempla, incluso, el propio Sistema Educativo. 
- El enfoque comunicativo, la pragmática y los medios tecnológicos están contribuyendo de modo muy significativo a su desarrollo educativo.

- La globalización y la interculturalidad ayudarán al desarrollo de proyectos y actuaciones educativas que generen una didáctica para el desarrollo de habilidades comunicativas en expresión oral. La necesidad de hablar más lenguas, el fenómeno de la inmigración y las técnicas de la didáctica de las segundas lenguas aportarán muchos recursos para el desarrollo de estas habilidades comunicativas de carácter universal.

- Conviene mimar la expresión oral desde perspectivas distintas: cognitivas, formales e, incluso, fónicas para el cuidado de la voz. Y también caer en la cuenta de que no existen recetas milagrosas, sino un trabajo educativo y pragmático constante.

\section{Bibliografía}

ALCOLEA, S. (1999), La oralización. Barcelona, Ariel.

ALLER MARTÍNEZ C. y ALLER GARCÍA, C. (1991), Juegos y actividades de lenguaje oral. Alcoy, Marfil.

CASSANY, D.; LUNA, M.; SANZ, G. (1994), Enseñar Lengua. Barcelona, Graó.

CHARLES, R. y WILLIAME, C. (1994), La communication orale. Paris, Nathan.

DEL RÍO, M.J. (1993), Psicopedagogía de la lengua oral: Un enfoque comunicativo. Barcelona, Universitat de Barcelona/ ICE./ Horsori.

FREIRE, P. (1970), La educación como práctica de la libertad. Madrid, Siglo XXI, 1989.

GIMENO TERRAZA, I. y Otras (2000), Expresión oral: Hablar bien en público. Barcelona, Larousse.

MENDOZA, A. Et. Alii. (1998), Conceptos clave en didáctica de la lengua y la literatura. Barcelona, Sedll/ Universitat de Barcelona/ Horsori.

MORALES, C.J. (2001), Guía para hablar en público. Madrid, Alianza Editorial: Cine y comunicación.

MORENO FERNÁNDEZ, F. (2002), Producción, expresión e interacción oral. Madrid, Arco Libros, S.L.

OESTREICHER, A. y RAMíREZ, J. (1992), Meloral: Método de oralidad para Melilla. Melilla, ProEmpleo, MEC.

RAMÍREZ MARTÍNEZ, J. (1997), "Lengua y cultura en Melilla: educación integral de adultos." En Cantero, J. et. Alii. Didáctica de la lengua y la literatura para una sociedad pluriligüe del siglo XXI. Barcelona, Sedll-Universitat de Barcelona: 665.

REYES, G. (1995), El Abecé de la Pragmática. Madrid, Arco Libros, S.L.

VV.AA. (1994), "Círculo", en Educación y trabajo. San Salvador (El Salvador, C.A.), Plan de Educación Básica de Adultos/ MINED y MEC.: 1-12.

VV.AA.(1995), Hablar en clase: Textos $n^{\circ}$ 3. Barcelona, Graó. 